\title{
Peaks and troughs: variations in the availability of therapeutic drug monitoring in critical care units across London
}

\author{
KE Grailey ${ }^{1 *}$, JM Singleton ${ }^{2}$, JB Simon ${ }^{2}$, JLC Wong ${ }^{2}$ \\ From ESICM LIVES 2015 \\ Berlin, Germany. 3-7 October 2015
}

\section{Introduction}

Therapeutic Drug Monitoring (TDM) is an evolving tool used to optimise the administration of antimicrobial agents; which are well documented to have toxic side effects [1]. In combination with increasing antimicrobial resistance and emphasis on cost-efficiency, provision of the optimal dose of antimicrobial therapy is a very attractive prospect.

Pharmacokinetic (PK) indices can be used to classify the efficacy of an antimicrobial agent. Critical illness may alter a patients PK behaviour [2] and therefore these patients may require alternative dosing regimens for optimal management [3].

\section{Objectives}

The aim was to evaluate the current use of TDM in Intensive Care Units (ICU's) across London, focusing on the availability of results, the range of drugs for which TDM is offered and presence of critical care specific regimens.

\section{Methods}

A 6 part questionnaire was developed, and data collection was achieved by telephone interviews with Critical Care Pharmacists at 27 London Hospitals between February and April 2015.

\section{Results}

All hospitals offered TDM, however there were significant differences in the application of this tool. TDM was reported to be available for Gentamicin, Vancomycin and Amikacin at almost all sites (27 units [100\%]; 26 units [96\%] and 19 units [70\%] respectively), with the majority providing onsite TDM.

${ }^{1}$ Barts Health NHS Trust, London, United Kingdom

Full list of author information is available at the end of the article
Gentamicin was universally available within 6 hours (27 units [100\%]). Vancomycin and Amikacin were frequently available within 6 hours (20 units [74\%] and 12 units [44\%] respectively). Teicoplanin was available within 6 hours in 5 units [20\%] yet took up to 24 hours in 4 units [15\%].

For commonly used drugs (Gentamicin, Vancomycin and Amikacin) most units followed Trust Specific Guidelines (27 units [100\%], 26 units [96\%] and 25 units [93\%] respectively), but ICU specific guidelines were only available in 6 units [23\%] for Gentamicin and 7 units [27\%] for Amikacin. Vancomycin had ICU specific guidelines in 19 units [73\%].

\section{Conclusions}

This initial survey across London demonstrates that whilst commonly used antimicrobial agents are often used with TDM to guide therapy, there is still large variation in the range of antimicrobials for which TDM is available. There was also shown to be discrepancy in the availability of test results, which may impact on patient care if potentially toxic or sub-therapeutic levels take

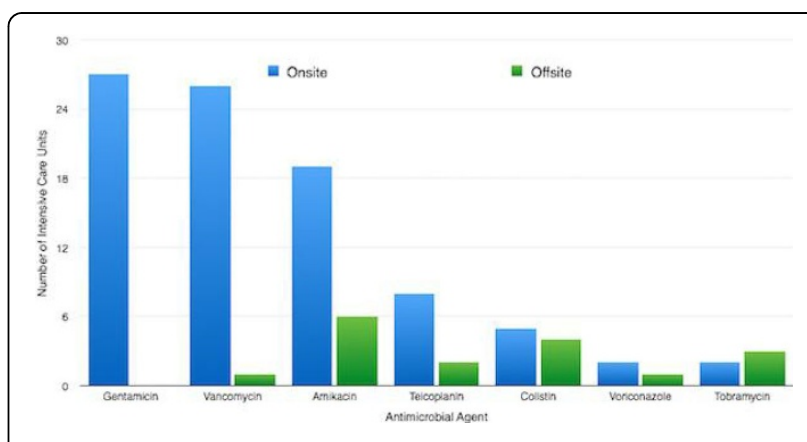

Figure 1 Number of Intensive Care Units offering TDM for each Antimicrobial Agent, separated according to onsite availability.

(c) 2015 Grailey et al.; This is an Open Access article distributed under the terms of the Creative Commons Attribution License (http:// creativecommons.org/licenses/by/4.0), which permits unrestricted use, distribution, and reproduction in any medium, provided the original work is properly cited. 


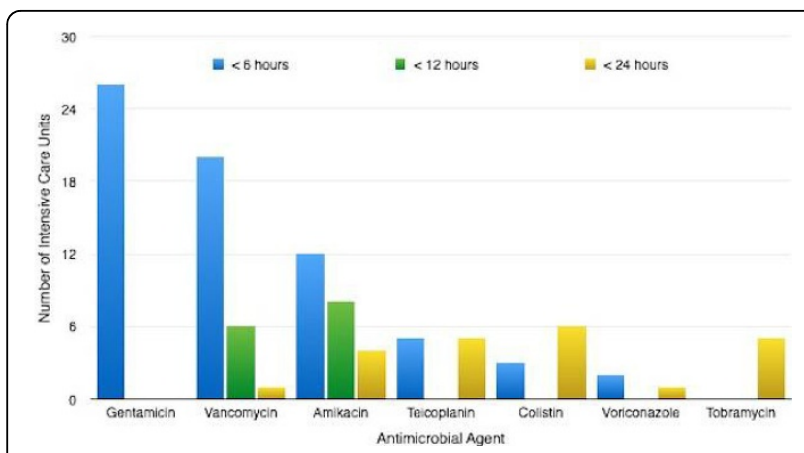

Figure 2 Availability of therapeutic Drug Monitoring- time for results to be accessible according to antimicrobial agent.

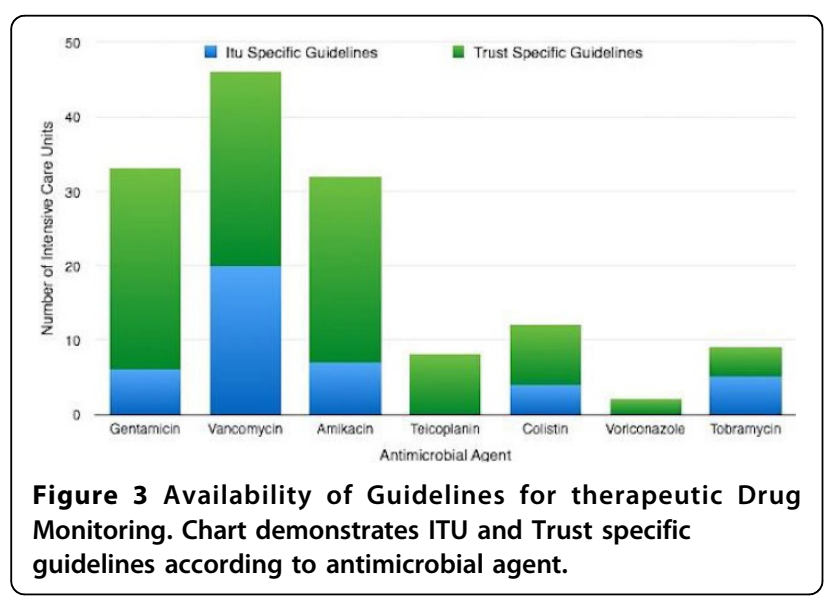

24 hours to be detected. It was also interesting to note that critical care specific guidelines were rare, despite the potential for pharmacokinetic differences in this patient group.

\section{Authors' details}

'Barts Health NHS Trust, London, United Kingdom. ${ }^{2}$ Imperial College London, London, United Kingdom.

Published: 1 October 2015

\section{References}

1. Roberts J, Norris R, Paterson D, Martin J: Therapeutic drug monitoring of antimicrobials. British Journal of Clinical Pharmacology 2011, 73(1):27-36.

2. Begg $E_{1}$ Barclay M, Kirkpatrick C: The Therapeutic Monitoring of Antimicrobial Agents. Br J Clin Pharmacol 1999, 47:23-30.

3. Vitrat $\mathrm{V}$, Hautefeuille, et al: Optimising antimicrobial therapy in critically ill patients. Infection and Drug Resistance 2014, 7:261-271.

doi:10.1186/2197-425X-3-S1-A397

Cite this article as: Grailey et al:. Peaks and troughs: variations in the availability of therapeutic drug monitoring in critical care units across London. Intensive Care Medicine Experimental 2015 3(Suppl 1):A397.

\section{Submit your manuscript to a SpringerOpen ${ }^{\circ}$ journal and benefit from:}

- Convenient online submission

- Rigorous peer review

- Immediate publication on acceptance

- Open access: articles freely available online

- High visibility within the field

- Retaining the copyright to your article

Submit your next manuscript at $>$ springeropen.com 